GHANA JOURNAL OF DEPARTMENT OF HEALTH, PHYSICAL EDUCATION AND RECREATION, SPORTS AND DANCE (GJOHPERSD)

Volume 10, Year 2017

A JOURNAL OF THE DEPARTMENT OF HEALTH, PHYSICAL EDUCATION AND RECREATION (HPER)

UNIVERSITY OF CAPE COAST

GHANA, WEST AFRICA 


\title{
REACTION TIME AND SPEED AS CORRELATES OF SPORTS INJURY AMONG STUDENTS OF FOOTBALL ACADEMIES IN NIGERIA
}

\author{
Tony Dansu, Rafiu, O. Okuneye \& Bidemi Idowu \\ Department of Human Kinetics, Sports and Health Education \\ Lagos State University, Ojo, Lagos, Nigeria
}

\begin{abstract}
Sports participation carries a risk for injuries, which may in some cases lead to permanent disability or death, hence; the need for attention on prevention. Physical fitness is a factor of sports injury. However, there is lack of sufficient evidence on relationship between specific components of physical fitness and sports injuries. This study therefore investigated reaction time and speed as they relate to sports injuries among students of football academies in Nigeria. Correlational research design was adopted for this study, and purposive sampling technique was used to select 128 students from three football academies. Standardised instruments and tests were used to measure the key parameters [i.e. speed and reaction time]. Physical characteristics that included weight, height, position of play, age, dominant leg and experience. Type of injury, part of body affected, event of injury and severity were also recorded. The data collection period was twelve weeks, and the data collected were analysed using percentage, mean, and Pearson's product moment correlation coefficient [PPMC] statistical tools. WINKS SDA package was used for analysis and hypothesis were tested at 0.05 level of significance. Findings of this study show that reaction time correlates with sports injuries sustained $[r(107)=0.23, p=0.02]$, while speed indicates no correlation $[r(107)=0.12, p=0.21]$.
\end{abstract}




\section{Dansu et al}

It is concluded that the level of reaction time acquired and maintained by students of football academies influence the frequency of injury sustained as well as the severity of such injury; while speed level does not have any significant influence on sustenance of injury among the target group.

Key Words: Speed, Reaction Time, Sports Injury, Football Academy, Injury Severity. 


\section{Introduction}

Issue of injury is a phenomenon of concern in sports, and it is very essential to employ every means of preventing it, especially in young sportsmen. Several authors (McCall et al, 2015; Saragiotto et al, 2014; Lauersen et al, 2013; Carol \& Eustice, 2006; Nader, 2005; Okuneye, 2001; Adegoke and Ogungbengbe, 2001; Odebiyi, Olalekan and Odunuga, 2001; Ituh, 1995; Gaya, 1991; Adeniyi 1991; Onuigbo, 1991; Adelekan 1991; Onifade, Agbojinmi and Ososanya, 1991) have emphasized the need to pay serious attention to various strategies for preventing sports injury.

According to Nader (2005), sports injury is preventable if factors that predispose players are identified and dealt with. Carol and Eustice (2006) identify some of these factors to include poor training methods, improper facilities and equipment, lack of conditioning and insufficient warm-up. Many authors (Ahmed et al, 2015; McCall et al, 2015; Ruddock, 2007; Ratzloff, Gillies \& Kochoorn, 2007; Ituh, 2005; Gieck, 2004; Conti, 2004; Pray and Pray, 2004; Lyon, 2001 Anderson, 2008; Okuneye, 2001; Adegoke and Ogungbengbe, 2001; Bello, 2000; Verstappen, Tweller, Hartgens \& Van-Mechelen, 1998) assert that physical fitness is a strong factor in the prevention of sports injury. Identifying areas of consideration for injury prevention, Gieck (2004) emphasises preseason-screening process, which should focus mainly on physical fitness. Emphatically, Ratzlaff, Gillies and Kochoorn (2007) state that being physically fit, is strongly associated with lower risk of strain injury.

Although, there are literatures on association between physical fitness and sports injury, there seems to be a lack of sufficient evidence on the relationship between specific components of physical fitness and sports injury (Blum and Beaudoin, 2000). Based on this gap, this study was designed to investigate the relationship between two components of physical fitness - reaction time and speed, and sports injury among students of Football Academies in Nigeria.

Reaction time, according to Piing (2009) is one of the required components of skill-related fitness, and it can be divided 
Dansu et al

to 3 main phases, i.e., stimulus detecting, stimulus interpreting and response programming. It is influenced by reaction delay and this kind of delay is mainly because of the time consumed for one to make a decision before initiating an action, where afferent nerve needs some time to send an impulse to Central Nervous System to be interpreted, and the brain needs time to decide what to do during response programming phase. There are many factors affecting reaction time, ranging from the nature of the stimulus information to the type of movement being performed (Piing, 2009; Schmidt \& Wrisberg, 2004). Citing Kosinski, Piing (2009) mentions that these factors are such as number of stimulusresponse alternatives, stimulus-response compatibility, arousal, age, gender, type of stimulus, exercise, fasting and stimulant drugs.

In relation to injury, Jacobson (2006) sees poor judgement and reaction time as major factors of injury among female football players. In line with this finding, Roshdi (2008; \& 2003) strongly recommends that good reaction time development should be one of the focuses of any good trainer for the purpose of injury prevention.

Speed is one of those physical qualities required for excellent performance in sports and it is needed to make sportsmen move their bodies or implements fast on the ground, in the water or in the air (Adeloye, 2003). It is usually difficult to separate or discuss speed in isolation of other qualities needed for sports performance. Indices such as strength and endurance are related to speed as they often influence it (Corbin, Welk, Corbin \& Welk, 2004; Wuest \& Bucher, 2003; Fahey, Insel \& Roth, 2001; Prentice, 1999; Howley \& Frank, 1992). There is dearth of literature on the relationship of speed to sports injury; however, Adeloye (2003) identifies this important component of physical fitness as vital in prevention of sports injury. Similarly, Gieck (2004) mentioned categorically that speed should be among the basic factors that must not be ignored while preparing sportsmen for competition and one of the major reasons for this emphasis is injury prevention. 
Reaction time and speed as correlates of Sports Injury among Students of Football

This study is therefore set to investigate if

Academies in Nigeria

i. there would be no significant correlation between reaction time and sports injury among the football academies' students;

ii. there would be no significant correlation between speed level and sports injury among the football academies' students.

\section{Methods and Procedure}

Research Design

The Correlational Research Design was employed in this study:

Where
$\mathbf{P}$
$\mathrm{O}_{1}$
$\mathrm{O}_{2}$

$\mathrm{P}=$ Participants - (Selected Students of Football Academies $)$

$\mathrm{O}_{1}=$ Observation on dependent variables (sports injury)

$\mathrm{O}_{2}=$ Observation on independent variables (Reaction time and speed)

\section{Participants}

Participants were purposively selected from three football academies at two different locations in Nigeria. The academies were selected based on criteria of students' population, availability of personnel/facilities and programmes/curricula. The academies include Pepsi Football Academy, Agege Lagos, FAKREM Football Academy, Surulere, Lagos, and Kwara Football Academy, Ilorin.

The table below shows the pattern of sample selection from the academies 
Dansu et al

Table 1

Frequency and Percentage of distributions on Sample Size of the Study

\begin{tabular}{llll} 
Academy & $\begin{array}{c}\text { Initial } \\
\text { Sample }\end{array}$ & Mortality & $\begin{array}{l}\text { Completion } \\
\text { Sample }\end{array}$ \\
\hline Pepsi (Male) & $44(34.4 \%)$ & $8(6.3 \%)$ & $36(28.1 \%)$ \\
$\begin{array}{l}\text { Pepsi } \\
\text { (Female) }\end{array}$ & $11(8.6 \%)$ & $3(2.3 \%)$ & $8(6.3 \%)$ \\
KFA & $46(35.9 \%)$ & $3(2.3 \%)$ & $43(33.6 \%)$ \\
FAKREM & $27(21.1 \%)$ & $5(3.9 \%)$ & $22(17.2 \%)$ \\
Total & $128(100 \%)$ & $19(14.8 \%)$ & $109(85.2 \%)$ \\
\hline
\end{tabular}

Table 1 shows that the initial research sample was 128 with mortality of $19(14.8 \%)$ and latter sample that completed the study was $109(85.2 \%)$. Of this sample size, $44(34.4 \%)$ were male students from Pepsi with mortality rate of $8(6.3 \%)$, while only 11 $(8.6 \%)$ were female students from Pepsi Academy with mortality rate of $3(2.3 \%)$. From Kwara Football Academy (KFA), there were $46(35.9 \%)$ students with $3(2.3 \%)$ mortality rate, and 27 (21.1\%) from FAKREM Football academy, having a mortality rate of $5(3.9 \%)$.

The use of purposive sampling technique was achieved through documentary analysis of the records of the academies with the permission of the managements of the academies, using regular attendance as the basis for sampling, to reduce drop-out rate. In the case of Pepsi and FAKREM Academies, all the students who were regular at training and were free from injury at the time of study served as sample of the study. But for Kwara Football Academy (KFA), only the junior and intermediate categories that were free from injury were involved in the study. The participants of the study were addressed on the purpose of the study, and their consents were gotten to participate in this study via duly filled 
copies of informed consent form. The Academy's management excused the senior category from taking part in the study due to tight schedule of programme.

\section{Instrumentation}

For the purpose of data collection, 50-metre Dash and Nelson Choice-Response Movement Test as described by Prentice (1999) were used to measure speed and reaction time of the participants respectively. The height and weight of the participants were measured following standards described by International Society for the Advancement of Kinanthropometry (ISAK, 2001). Their ages were sought from the official records of the academies and were cross-checked via interview of the participants. These were recorded in years to the nearest birthday.

A self-developed data recording form titled Physical Fitness and Sports Injury (PFSI) Data Form was designed by the researchers. This form is in three parts. Part A records information on physical characteristics and personal data of participants. These include age, height, weight, and sex. Part $\mathrm{B}$ records data on the measured physical fitness components, and the third part (Part C) deals with data on sports injury, which included date of injury, type of injury, affected part of body and severity of injury

\section{Administration of Instrument}

All tests and measurements were carried out at the training complex of each of the academies, and this spanned over the period of twelve weeks. During this period, measurement on selected physical fitness components were taken three times; each at the beginning of every four weeks, counting from the first day of tests and measurements. This is to ascertain current fitness level of participants as at the period they sustain injury, if there is any case. Duplicates of Physical Fitness and Sports Injury (PFSI) data form for the participants were kept with a designated officer in each of the academies who served as research assistant for recording and keeping records of injury sustained by the students. The original copies of the data forms were with the researcher, and these were 
Dansu et al

often updated as at when due. This is to avoid loss of the original sources of data.

\section{Data Analysis}

The injuries sustained by the participants of this study were scored based on their severity as defined by Federation Internationale de Football Association (FIFA) Medical Assessment and Research Centre (F-MARC, 2006) and Union of European Football Association (UEFA) Consensus Discussion (Hagglund, Walden, Bahr, \& Ekstrnad, 2005). The cut-off points for the different categories of injury severity were then allotted points as follows:

$$
\begin{aligned}
& \checkmark \text { slight }(1-3 \text { days })=1 \text { point } \\
& \checkmark \text { minor }(4-7 \text { days })=2 \text { points } \\
& \checkmark \text { mild }(8-15 \text { days })=3 \text { points } \\
& \checkmark \text { moderate }(16-28 \text { days })=4 \text { points; and } \\
& \checkmark \text { major }(\text { above } 28 \text { days })=5 \text { points. }
\end{aligned}
$$

Note: Days in the brackets indicate number of days the injured players spent out of active participation.

All data collected were coded and subjected to statistical analysis. Descriptive statistics of Frequency Counts, Simple Percentage, Mean, Range and Standard Deviation were used to describe the results, while Pearson's Product Moment Correlation Coefficient was used to test the stated hypotheses at 0.05 level of significance. Pictorial analysis of scatter plots was also used to further explain results of tested hypotheses. Data analysis was carried out using statistical package of TexaSoft, WINKS SDA Software (6th Ed, 2007). 


\section{Results}

\section{Table 2}

PPMC Result on Reaction Time of Participants and Sports Injury

$\begin{array}{llllllllll}\text { Variables } & \text { No } & \mathbf{X} & \text { SD } & \text { df } & \mathbf{r} & \mathbf{r}^{2} & \mathbf{T} & \mathbf{P} \\ \begin{array}{l}\text { Reaction } \\ \text { T. }\end{array} & 109 & 2.10 & 0.38 & & & & & \\ & & & & 107 & 0.23 & 0.05 & 2.40 & \mathbf{0 . 0 2 *}\end{array}$

Injury $\quad 109 \quad 1.75 \quad 2.04$

* = significant at 0.05

The result presented in table 2 was on the test of the hypothesis that there would be no significant correlation between reaction time and sports injury among the football academies'students. An evaluation was made of the linear relationship between Reaction Time and Injury using Pearson's correlation. This analysis indicates a statistically significant linear relationship between reaction times of the participants and sports injury sustained by them during the course of this study $[\mathrm{r}(107)=0.23, \mathrm{p}=0.02]$. This result is further described in Figure 1. 


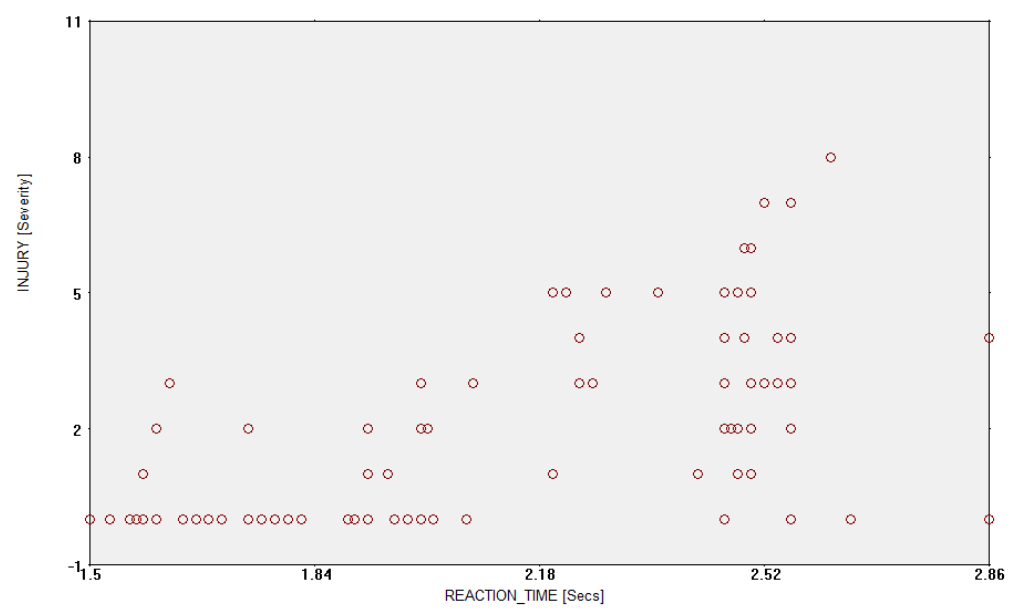

Figure 1: Scatter plot on Reaction Time and Sports Injury

The scatter plot in figure 1 indicates that participants with poor reaction time sustained most of the injuries as well as injuries with greater severity recorded in this study. Most of those who sustained injury in this study recorded reaction time greater than 2 seconds, which indicates poor level of reaction time for footballers.

\section{Table 3}

PPMC Result on Speed Level of Participants and Sports Injury

\begin{tabular}{lcccccccc} 
Variables & No & $\mathbf{X}$ & SD & df & $\mathbf{r}$ & $\mathbf{r}^{2}$ & $\mathbf{T}$ & $\mathbf{P}$ \\
\hline Speed & 109 & 7.29 & 1.00 & & & & & \\
& & & & 107 & 0.12 & 0.02 & 1.26 & $\mathbf{0 . 2 1}$
\end{tabular}

Injury $\quad 109 \quad 1.75 \quad 2.04$


Reaction time and speed as correlates of Sports Injury among Students of Football Academies in Nigeria

The result presented in table 3 was on test of the hypothesis that there would be no significant correlation between speed level and sports injury among the football academies' students. An evaluation was made of the linear relationship between Speed and Injury using Pearson's correlation. This analysis indicates no statistically significant relationship between speed levels of the participants and injury sustained during the course of this study [ $\mathrm{r}$ $(107)=0.12, p=0.21]$. Figure 2 describes this result further.

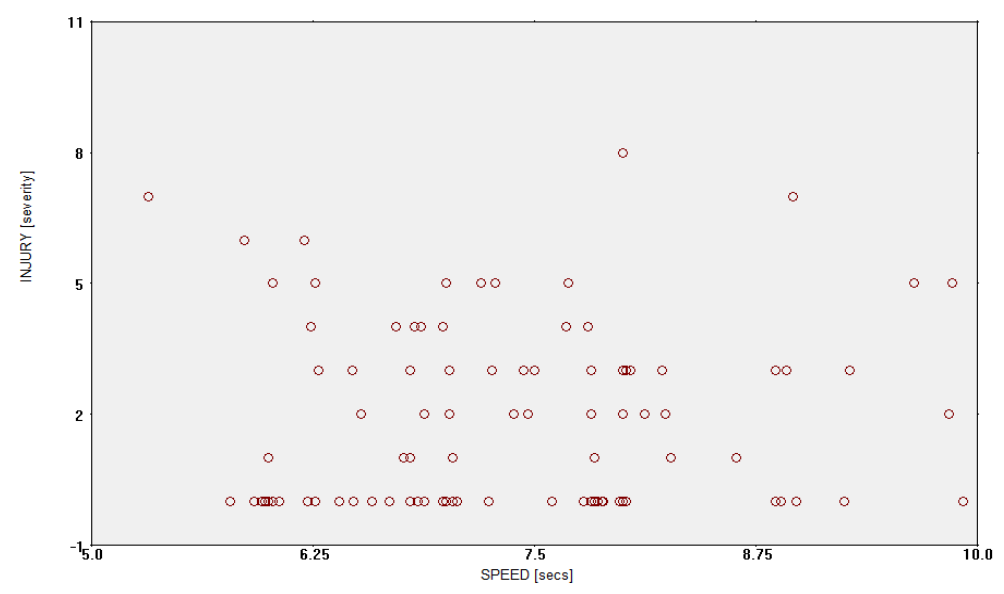

Figure 13: Scatter Plot on Speed Level and Injury

The above scatter plot shows no relationship between speed level of the participants and injury sustained during the course of this study, as there is no definite direction shown in the plot.

\section{Discussion}

Results of this study show a significant correlation between reaction time and sports injury (see table 2 and figure 1). According to Piing (2009), reaction time is one of the required components of skill-related fitness, and in relation to sports injury, Jacobson (2006) sees poor judgement and reaction time as major factors of injury among female football players. This study 
Dansu et al

establishes that most football players who sustained injury recorded reaction times greater than 2 seconds, which is an indication of poor level of reaction time for footballers. In line with this finding, Roshdi (2008) strongly recommends that good reaction time development should be one of the focuses of any good trainer for the purpose of injury prevention. Along with speed, coordination and agility, Gieck (2004) opines that good reaction time will keep one out of potential injury producing situations.

This study found no correlation between speed and sports injury among football players. Result indicates no clear speedbased cut-off point for injury sustenance among the players (see table 3 and figure 2). There is a dearth of literature on the relationship between speed and sports injury. Although, Adeloye (2003) identifies this component of physical fitness as vital in prevention of sports injury, and Gieck (2004) states that speed should be among the basic factors that must not be ignored while preparing sportsmen for competition; but these positions have no empirical bases. However, speed is one of those physical qualities required for excellent performance in sports and it is needed to make sportsmen react fast or move their bodies or implements fast on the ground, in the water or in the air as the case may be (Adeloye, 2003). It is usually difficult to separate or discuss speed in isolation of other qualities needed for sports performance. Indices such as strength and endurance are related to speed as they often influence it (Corbin, Welk, Corbin \& Welk, 2004; Wuest \& Bucher, 2003; Fahey, Insel \& Roth, 2001; Prentice, 1999; Howley \& Frank, 1992). The finding of this study could be as a result of variation of playing positions of footballers. Different roles by players in football may require different levels of speed.

\section{Conclusion}

Based on the findings of this study, the level of reaction time acquired and maintained by students of football academies influence the frequency of injury sustained as well as the severity of such injury; while speed level does not have any significant influence on sustenance of injury among the target group. 


\section{Recommendations}

This study recommends the following:

i. Football academies, club owners, state and national football administrators should endeavour to engage exercise physiologists as part of their academies, clubs or teams' personnel. This is to ensure adequate and appropriate training programme management for the sportsmen for development of appropriate level of each component of physical fitness. Football academies and club managements should have database on physical fitness of all their students and players respectively. This will enable proper monitoring of students' fitness levels and necessary adjustment when the need arises.

ii. Further studies on relationship between other physical fitness indices and sports injury should be carried out on footballers of similar age. This will form basis for comparison with this study to identify areas of differences in terms of sports injury and physical fitness. Further studies should also be extended to other sports, especially team and contact sports such as basketball and handball that also record high rate of injury.

iii. Training programmes should be well planned such that adequate coverage for the build up of reaction time and other components of physical fitness by students of football academies is ensured.

\section{References}

Adegoke, B. O. A. \& Ogungbangbe, S. T. (2001). Prevalence of joint laxity in athletic and non-athletic undergraduates. Journal of the Nigeria Medical Rehabilitation Therapists, 6 (2), 26-29.

Adelekan, T. A. (1991). Injury at the NATCEGA '90 Games.

Sports Science and Medicine, 1, 301-308.

Adeloye E. O. (2003). Developing and evaluating norms on selected health and performance fitness variables for university female athletes in South West of Nigeria. 
Dansu et al

Unpublished Doctoral Research Proposal. Ibadan: University of Ibadan.

Adeniyi, B. (1991). Injury prevention in school sports. Sports Science and Medicine, 1, 249-254.

Ahmed O. H., Hussain AW, Beasley I, et al (2015). Enhancing performance and sport injury prevention in disability sport: moving forwards in the field of football. British Journal of Sports Medicine, 49:566-567

Anderson, O. (2008). Injury prevention tips (online). Available: http://www.sportsinjurybulletin.com. 18/02/08.

Bello, N. (2000). Lack of physical fitness causes higher sports injury rates among women (online). Available: http://hbns.org 14/04/08.

Blum, J.W. \& Beaudoin C.M. (2000). Does Flexibility Affect Sport Injury and Performance? (online). Available: http://findarticles.com 12/02/09.

Carol, B. \& Eustice. R. (2006). Sports injury guide: The common types of sports injury (online). Available: http://www.healthline.com. 10/02/08.

Conti, J. V. (2004). Relationship between flexibility and sports injury (online). Available: http://www.efdeportes.com. 12/02/08.

Corbin, C. B., Welk, G. J., Corbin, W. R. \& Welk, K. A. (2004) Concepts of physical fitness: Active life styles for wellness. Boston: McGraw Hill Company.

Fahey, T.D. Insel P.M. \& Roth, W.T. (2001). Fit and well: Core concepts and labs in physical fitness and wellness. California: Mayffield Publishing Co.

FIFA Medical Assessment and Research Centre (F-MARC, 2006) FIFA sets new definitions and procedures for injury in football(online).Available: http://www.medicalnewstoday.com 14/02/08.

Gaya, M. W. U. (1991). Injury prevention in sports. Sports Science and Medicine, 1, 243-248.

Gieck, J. H. (2004). Sports injury prevention for optimal athletic performance (online). Available: http://www.theacc.com. 10/02/08. 
Reaction time and speed as correlates of Sports Injury among Students of Football Academies in Nigeria

Hagglund, M. Walden, M. Bahr R \& Ekstrand, J. (2005). Methods for epidemiological study of injury to professional football players: Developing the UEFA model. British Journal of Sports Medicine, 39, 340-346.

Howley, E. T. \& Frank, B. D. (1992) Health fitness instructor's handbook. Champaign: Human Kinetics Books.

International Society for the Advancement of Kinanthropometry (ISAK, 2001). International Standard for anthropometrics assessment. Potchefstroom:ISAK

Ituh, M. C. (1995). Fitness for athletes: The way to prevent sports injury. Sports Science and Medicine Journal, 5, 95-99.

Jacobson, I. [2006]. Injury among female football players. Unpublished Doctoral Thesis. Department of Health Science, Division of Physiotherapy, Lulea University of Technology, Lulea.

Lauersen J.B, Bertelsen D.M. \& Andersen L.B. (2013). The effectiveness of exercise interventions to prevent sports injuries: a systematic review and meta-analysis of randomised controlled trials (online). British Journal of Sports Medicine Online. doi: 10.1136/bjsports-2013092538

Lyon, R. M. (2001). Preventing injury in young football players (online). Available: http://healthlink.mcw.edu. 14/02/08.

McCall A, Davison M, Andersen TE, et al (2015). Injury prevention strategies at the FIFA 2014 World Cup: perceptions and practices of the physicians from the 32 participating national teams. British Journal of Sports Medicine, 49:603-608.

Nader, R. (2005). Sports injury prevention (online). Available: http://two.pairlist.net. 10/02/08.

Odebiyi, D. O., Olalekan, A. T. \& Odunuga, O. A. C. (2001). Sports medicine: the role of a sports physiotherapist. Journal of the Medical Rehabilitation Therapists, 6(1), 2124. 
Dansu et al

Okuneye, R. O. (2001). Sports behaviour of students in Lagos area: Effect on knowledge of sports injury. Journal of the Medical Rehabilitation Therapist, 6(1), 1-3.

Onifade, A., Agbonjinmi, A., and Ososanya, D. (1991). Sports injury among University athletes. Sports Science and Medicine, 1, 255-262.

Onuigbo, G. O. C. (1991). Injury prevention in sports. Sports Science and Medicine, 1, 263-266.

Piing, Y.N. (2009). Reaction time and sports performance [online]. Available: http://www.medic.usm. 18/04/09.

Pray, W. S. \& Pray, J. J. (2004). Prevalence of sports injury and epidemiology(online).Available:http://www.medscrape.com . 12/02/08.

Prentice, W. E. (1999). Fitness and wellness for life $\left(6^{\text {th }} \mathrm{Ed}\right)$. Boston: McGraw Hill. Ratzloff, C. R., Gillies, J. H. \& Koehroorn, M. W. (2007). Work-related repetitive strain injury and leisure-time physical activity. Arthritis Care \& Research, 57(3), 495-500.

Roshdi, R. (2003). Tips to prevent football injury (online). Available: http://www.ameinfo.com. 14/02/08.

Roshdi, R. (2008). Tips to preventing football injury [online]. Available: http://www.ameinfo.com 14/02.08.

Roshdi, R. (2008). Tips to preventing football injury [online]. Available: http://www.ameinfo.com 14/02.08.

Ruddock, A. (2007). Injury prevention, agility and technique (online). Available: http://www.peakspeed.net. 16/02/08.

Saragiotto, B. T., Di Pierro, C., \& Lopes, A. D. (2014). Risk factors and injury prevention in elite athletes: a descriptive study of the opinions of physical therapists, doctors and trainers. Brazilian Journal of Physical Therapy, 18(2), 137-143.

Schmidt, R. A., and Wrisberg, C. A. (2004). Motor learning and performance. (3rd Ed.). USA: Human Kinetics.

Verstappen, F. T., Twellaar, M., Hartgens, F. \& Van-Machelen, W. (1998). Physical fitness and sports skills in relation to sports injury: A four-years prospective investigation of sports injury among physical education students. 
Reaction time and speed as correlates of Sports Injury among Students of Football Academies in Nigeria

International Journal of Sports Medicine, 19(8), 586591.

WINKS Statistical Data Analysis Package (2007).TexaSoft, WINKS SDA Software (6th Ed). Texas: Cedar Hill.

Wuest, A. W. \& Bucher, C.A. (2003). Foundations of physical education, exercise science and sport $\left(14^{\text {th }} \mathrm{Ed}\right.$.). Boston: McGraw Hill. 